\title{
High impact force attenuation of reinforced concrete systems
}

\author{
Y. Kim, T. El-Korchi \& K. S. Arsava \\ Department of Civil and Environmental Engineering, \\ Worcester Polytechnic Institute (WPI), Worcester, MA, USA
}

\begin{abstract}
This paper presents the application of smart control technology to reinforced concrete systems for high impact force attenuation. The smart reinforced control system is developed through the integration of reinforced concrete beams, smart control devices, sensors, and signal processors. Various combinations of input and output signals are applied to the smart reinforced concrete beams: impact forces and current signals are used as input signals while accelerations and displacements are used as output signals. Based on the set of input-output signals, a nonparametric model is developed to predict the nonlinear behaviour of smart concrete beam systems. It is demonstrated from the experimental studies that the proposed model is effective in predicting the nonlinear impact responses of the reinforced concrete systems.

Keywords: high impact forces, impact force attenuation, reinforced concrete systems, smart control technology, system identification, structural control, fuzzy logic model, magnetorheological (MR) damper.
\end{abstract}

\section{Introduction}

The use of concrete systems as structural components, such as bridge girders, has become wide-spread due to superior strength to weight ratios [1]. However, the use of optimized concrete systems introduces new concerns about the vibration, fire resistance and endurance of such structural members [2, 3]: for example, wheel loads on bridge spans with standard bolted rail joints can produce impact loads that may exceed the design load as shown in Figure 1. A collision-induced impact and/or a fuel tanker accident on a bridge or under an overpass will affect the structural integrity of members as shown in Figure 2 [4]. 


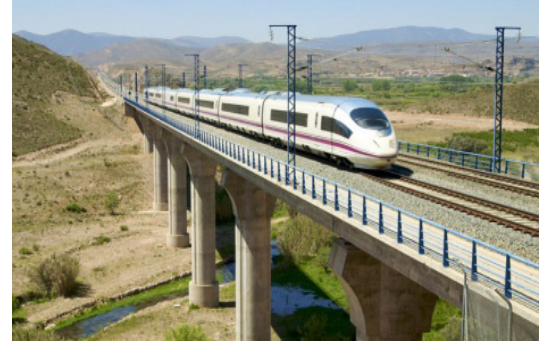

Figure 1: Traffic-induced vibration of concrete bridges.

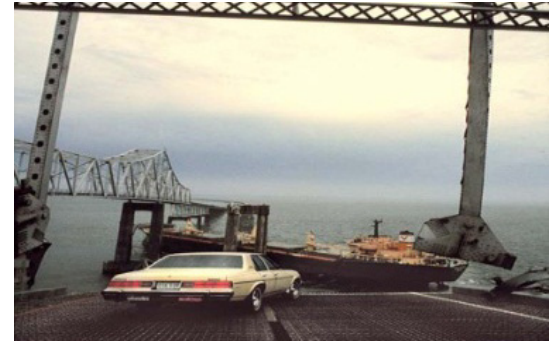

Figure 2: Collision-induced impact forces of waterway vessel.

Several such incidents have occurred on major interstate highways, beltways, bridges and overpasses in the US. In such scenarios, the impact led to a weakening of the long span concrete systems, by reducing the stiffness of structural girders and beams and possibly resulting in the collapse of bridge structures. However, such damage mechanisms of structures can be significantly reduced through high impact force attenuations, using smart control systems $[5,6]$. It is also expected that the reduced damage (e.g. less cracking in concrete) results in delayed stress increase within the structural components. In addition, improved dynamic behavior will result in reduced maintenance and an extended service life of concrete bridges.

However, one of the most challenging but important tasks in the smart control system design for the impact force attenuations is the development of an accurate explicit mathematical model of the dynamical systems under high impact loads to be controlled. The reason is that the mathematical information related to the dynamic system is used for calculation of control forces [7]. However, there is no available approach in the literature about how to model an integrated structure-MR damper system under high impact loads (including the interaction effects between a structure and MR dampers). With this in mind, a mathematical model for describing the nonlinear behavior of the integrated concrete-MR damper systems under high impact loads is developed. The paper is organized as follows: Section 2 discusses about the system identification process using a Takagi-Sugeno fuzzy modelling framework. Experimental studies and modelling results are described in Section 3. Concluding remarks are given in Section 4.

\section{System identification}

\subsection{Takagi-Sugeno (TS) fuzzy model}

In 1985, Takagi and Sugeno [8] developed a systematic methodology for a fuzzy reasoning using linear functions in the consequent part. Because the TS-fuzzy 
model uses linear functions in the consequent part, the defuzzification procedure is not required. A typical fuzzy rule for the TS fuzzy model has the form

$$
\begin{gathered}
\mathrm{R}_{j} \text { : If } z_{\mathrm{FZ}}^{1} \text { is } p_{1, j} \text { and } z_{\mathrm{FZ}}^{2} \text { is } p_{2, j} \text { and } \cdots \text { and } z_{\mathrm{FZ}}^{i} \text { is } p_{i, j} \\
\text { Then, } \mathbf{y}_{j}(k)=\sum_{i=1}^{n} \mathbf{a}_{i, j} \mathbf{y}_{j}(k-i)+\sum_{i=1}^{m} \mathbf{b}_{i, j} \mathbf{u}_{j}(k-i),
\end{gathered}
$$

where $\mathrm{R}_{j}$ is the $j^{\text {th }}$ rule of the fuzzy model; $z_{\mathrm{FZ}}^{i}$ is the premise variable; $\mathrm{u}(\mathrm{k})$ and $\mathrm{y}(\mathrm{k})$ are the input and output, respectively; $\mathbf{a}_{i, j}$ and $\mathbf{b}_{i, j}$ are the consequent parameters to be estimated; $n$ and $m$ are the number of delay steps in the output and input signals, respectively. The TS fuzzy model-based reasoning is to simply compute weighted mean values

$$
\mathbf{y}_{\text {final }}=\frac{\sum_{j=1}^{N_{r}} \mathbf{w}_{j} \mathbf{y}_{j}(k)}{\sum_{j=1}^{N_{r}} \mathbf{w}_{j}},
$$

where $N r$ is the number of the fuzzy rules and

$$
\mathbf{w}_{j}=\prod_{i=1}^{n} \mu_{i, j}\left(z_{\mathrm{FZ}}^{i}\right),
$$

where $\mu_{i, j}\left(z_{\mathrm{FZ}}^{i}\right)$ is the grades of membership of $z_{\mathrm{FZ}}^{i}$. In this paper, the premise parameters are determined using the fuzzy C-means clustering algorithm [9] while the consequent parameters are optimized via the backpropagation neural network algorithm [10].

\subsection{Identification of high impact responses}

Figure 3 shows the configuration of the structural system equipped with nonlinear hysteretic actuators. In this study, two MR dampers are implemented into the structural system for impact force attenuations.

In this paper, a two-input and single output TS fuzzy model is developed such that the fuzzy model effectively predicts the impact responses of the smart structures. The high impact force and current signals are used as the $1^{\text {st }}$ and $2^{\text {nd }}$ input signals while either displacement or acceleration responses are used as the output signal. 


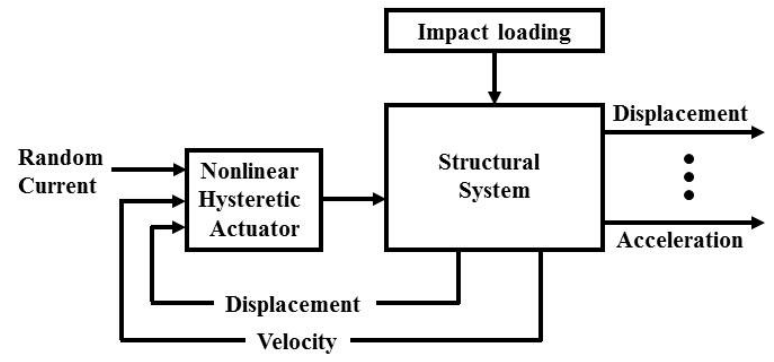

Figure 3: Nonlinear system identification process of integrated structurecontrol system under high impact loads.

\section{Experimental study}

\subsection{Experimental setup}

To demonstrate the effectiveness of the TS fuzzy modelling framework, an experimental setup is established in order to generate many sets of input and output data as shown in Figure 4(c) to (d). Reinforced concrete beams measuring $10 \times 10 \times 100 \mathrm{~cm}$ were constructed as shown in Figure 4(a). The longitudinal steel

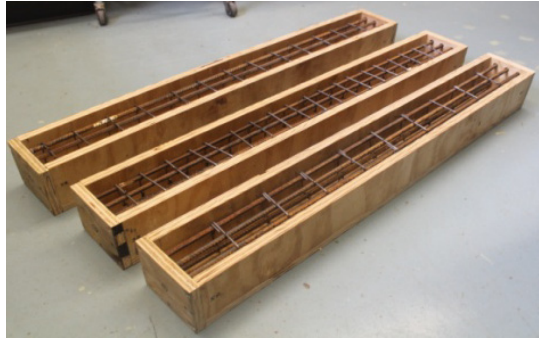

(a)

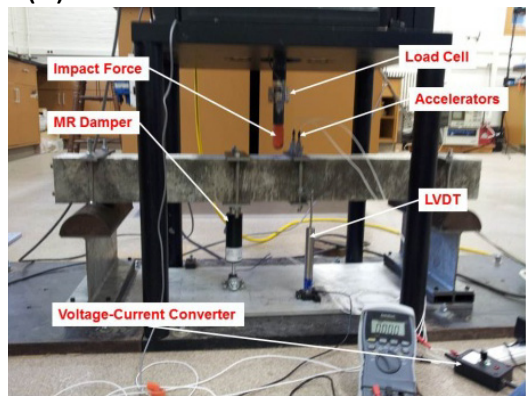

(c)

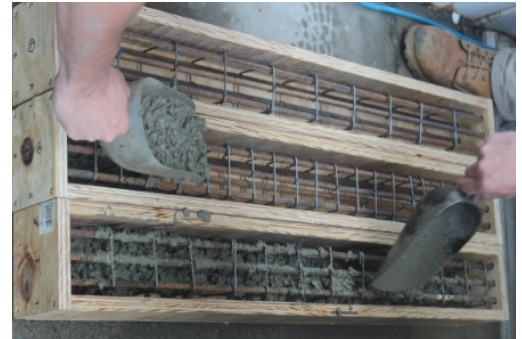

(b)

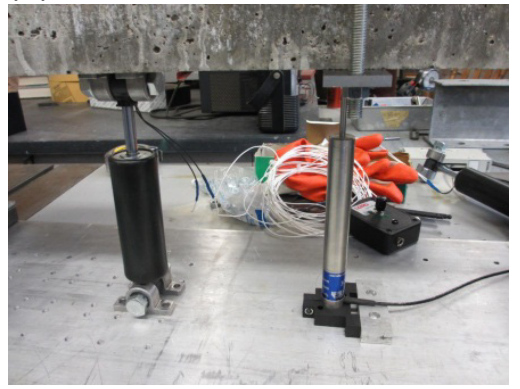

(d)

Figure 4: Configuration of smart concrete beam construction and data acquisition system setup to study dynamic behavior of structures equipped with MR dampers. 
consisted of deformed bars having a yield of 248MPa with $7.5 \mathrm{~cm}$ in diameter. Three longitudinal bars were placed in the tension and compression zone. Stirrups consisted of $0.25 \mathrm{~cm}$ steel wire spaced between $5,7.5$ and $10 \mathrm{~cm}$ for different beams. Portland cement concrete mixtures with a maximum aggregate size of $6.5 \mathrm{~mm}$ were used as shown in Figure 4(b). The concrete beams were cured in a curing room for over three weeks. At time of testing, the compressive strength of the concrete was $26 \mathrm{MPa}$ and the modulus of elasticity $E$ was $15 \mathrm{GPa}$.

\subsection{Results}

Figure 5 compares the measured data with the predicted model. It is clearly seen that the proposed TS fuzzy model effectively predicts nonlinear behavior of the structural concrete system equipped with MR dampers. This demonstrates the feasibility of the TS fuzzy model for structural health monitoring and structural control system design.

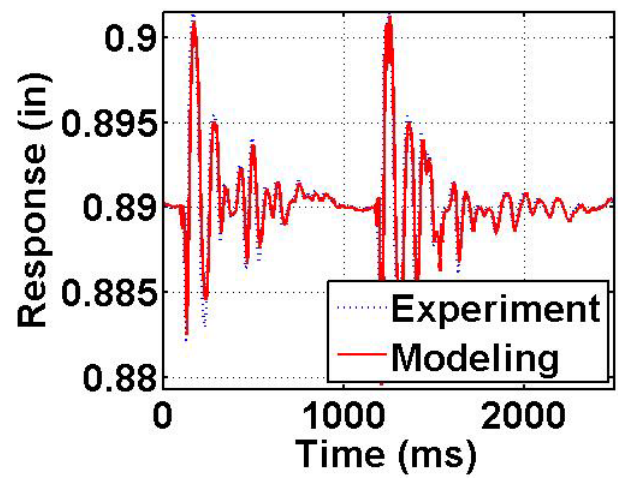

Figure 5: Comparison of the original data with the TS fuzzy model under the high impact loads.

\section{Conclusions}

This paper presents the application of smart control technology to concrete system design under high impact loads. Nine concrete beams are designed and manufactured and then those are integrated with magnetorheological (MR) dampers. Based on the set of input and output data collected from the integrated concrete-MR damper system subjected to high impact forces, a TS fuzzy model was developed. It is shown from the simulation that the TS fuzzy model effectively predicts nonlinear impact responses of smart concrete beam systems equipped with MR dampers.

\section{References}

[1] K. Hong, S. Lee, Y. Kim, H. Chun, J. Lee and S. Kim (2012), Precast Concrete Both-end Cantilevered Beam employing X-bracing Rebars, Materials and Structures, in review. 
[2] Z. Huszar (2008), Vibrations of Cracked Reinforced and Prestressed Concrete Beams, Architecture and Civil Engineering, 6, 155-164.

[3] V. Motevalli and T. El-Korchi (2006), Investigation of Fire Performance of Structural Members Incorporating Fiber Reinforced Plastic Composites used Scaled Experimental Enclosure Fires, $4^{\text {th }}$ International Workshop Structures in Fire-SiF'06, Aveiro, Portugal, May 10-12.

[4] G.R. Consolazio, M.T. Davidson, D.J. Getter (2010), Vessel Crushing and Structural Collapse Relationships for Bridge Design, Florida Department of Transportation, Final Report.

[5] Y. Kim, R. Langari and S. Hurlebaus (2009) Semiactive Nonlinear Control of a Building with a Magnetorheological Damper System, Mechanical Systems and Signal Processing, 23, 300-315.

[6] R. Mitchell, Y. Kim and T. El-Korchi (2012a) Wavelet-based Neuro-Fuzzy Controller for Vibration Mitigation of High-rise Buildings, Journal of Vibration and Control, in press.

[7] Y. Kim, R. Langari and S. Hurlebaus (2011) MIMO Fuzzy Identification of Building-MR damper System, International Journal of Intelligent and Fuzzy Systems, 22, 1-21.

[8] T. Takagi and M. Sugeno (1985), Fuzzy Identification of Systems and Its Applications to Modeling and Control, IEEE Transactions on Systems, Man, and Cybernetics, 15, 116-132.

[9] J.S. Kim, Y. Kim and T. El-Korchi (2012), Fuzzy Identification of Seismically Excited Smart Systems," Structural Seismic Design Optimization and Earthquake Engineering: Formulations and Applications, IGI-Global, Inc., Nikos Lagaros (ed.), 323-341.

[10] R. Mitchell, Y. Kim and T. El-Korchi (2012b) System Identification of Smart Structures using Wavelet Neuro-Fuzzy Model, Smart Materials and Structures, in press. 